\title{
Preparation of controlled porosity carbon aerogels for energy storage in rechargeable lithium oxygen batteries
}

\author{
Mojtaba Mirzaeian, Peter J. Hall* \\ Department of Chemical and Process Engineering, University of Strathclyde, Glasgow, G1 1XJ, Scotland, UK
}

\begin{abstract}
A B S T R A C T
Porous carbon aerogels are prepared by polycondensation of resorcinol and formaldehyde catalyzed by sodium carbonate followed by carbonization of the resultant aerogels in an inert atmosphere. Pore structure of carbon aerogels is adjusted by changing the molar ratio of resorcinol to catalyst during gel preparation and also pyrolysis under $\mathrm{Ar}$ and activation under $\mathrm{CO}_{2}$ atmosphere at different temperatures. The prepared carbons are used as active materials in fabrication of composite carbon electrodes. The electrochemical performance of the electrodes has been tested in a $\mathrm{Li} / \mathrm{O}_{2}$ cell. Through the galvanostatic charge/discharge measurements, it is found that the cell performance (i.e. discharge capacity and discharge voltage) depends on the morphology of carbon and a combined effect of pore volume, pore size and surface area of carbon affects the storage capacity. $\mathrm{A} \mathrm{Li} / \mathrm{O}_{2}$ cell using the carbon with the largest pore volume $\left(2.195 \mathrm{~cm}^{3} / \mathrm{g}\right)$ and a wide pore size $(14.23 \mathrm{~nm})$ showed a specific capacity of $1290 \mathrm{~mA} \mathrm{~h}^{-1}$.
\end{abstract}

\section{Introduction}

Increase in the price of fossil fuels and their carbon foot prints have led to the utilization of cheap and renewable energy sources such as the wind and solar power as alternative energy supplies. Since these energy sources are intermittent and on the other hand as energy demand for a wide range of applications from microchips to portable electronics to hybrid electric vehicles increases, energy storage systems play a more significant role in our lives and their performances have to be further improved to meet the higher requirements of future systems.

Because of their inherent simplicity in concept batteries are at the forefront of the electrical energy storage systems. The amount of energy per mass or volume that a battery can deliver is a function of the cell's voltage and capacity. The stored energy content of a battery can be maximized by having a large chemical potential difference between the two electrodes; making the mass (or volume) of the reactants per exchanged electron as small as possible; and by ensuring that the electrolyte is not consumed in the chemistry of the battery [1].

Lithium is an extremely light metal and has the lowest electronegativity of the standard cell potential $(-3.045 \mathrm{~V})$ in the existing metals [2]. It can donate electrons the most easily to form positive ions [3]. Owing to these properties, lithium based batteries have a high energy density, high specific energy and high operating voltage, and are expected as the potential power sources for many applications [4].

Commercial rechargeable lithium batteries use lithium transition metal oxides, typically $\mathrm{LiCoO}_{2}$, as cathode and graphite as anode [5]. Their specific capacity depends on the capacities of both the cathode and anode materials. Graphite has a theoretical capacity of $372 \mathrm{~mA} \mathrm{~h} \mathrm{~g}^{-1}$ [6]. Energy storage in these batteries is limited by the cathode and does not exceed $200 \mathrm{~mA} \mathrm{~h}^{-1}$ [7].

The capacity of a lithium battery system can be enhanced remarkably by using a completely different approach which combines Li as anode directly with oxygen as cathode active material in a Li/oxygen cell $[7,8]$. Oxygen accessed from the environment is reduced catalytically on an air electrode surface to form either an oxide or peroxide ion. The catalytically formed anions react with lithium cations supplied by the anode and delivered by the electrolyte to form $\mathrm{Li}_{2} \mathrm{O}_{2}$ on the air electrode surface during discharge process. Oxygen, the unlimited cathode active material, is not stored in the battery and therefore the theoretical specific energy of the $\mathrm{Li} / \mathrm{O}_{2}$ cell $\left(11400 \mathrm{Wh} \mathrm{kg}^{-1}\right.$ excluded and $5200 \mathrm{Wh} \mathrm{kg}^{-1}$ included oxygen) is the highest among various metal/oxygen batteries and is still much larger than that achievable using a conventional lithium ion battery [8].

The $\mathrm{O}_{2}$ electrode in lithium/oxygen batteries is a carbon electrode having a porous structure in which several electrochemical and transport processes occur simultaneously. The porous 
structure acts as gas transport pores for the diffusion of oxygen to the carbon-electrolyte interface (reaction zone), formation and storage of $\mathrm{Li}_{2} \mathrm{O}_{2}$ during the discharge process and also electrochemical decomposition of $\mathrm{Li}_{2} \mathrm{O}_{2}$ during the charge process. The kinetics of oxygen diffusion through the cathode limits the performance of the Li/oxygen cells [9]. It has been also discussed that the end-ofdischarge of the cell is reached when the carbon pores are filled or choked by the deposition of $\mathrm{Li}_{2} \mathrm{O}_{2}[7,10]$. Electrolyte is the only media for the transfer of lithium ions between cathode and anode during charge/discharge and therefore diffusion of electrolyte into the porous structure of the electrode is another important parameter for energy storage in lithium/oxygen batteries.

This shows that the cell performance strongly depends on the morphology and structure of the carbon. Therefore the main challenge in this issue is the development of new carbon based electrodes to improve the kinetics of the air cathode and enhance the capacity; energy and power densities; and the stability of the energy delivered by these systems. Engineering and chemical advances are also required to prevent the access of $\mathrm{CO}_{2}$ and $\mathrm{H}_{2} \mathrm{O}$ which could react with either $\mathrm{Li}_{2} \mathrm{O}_{2}$ or lithium metal.

The use of nanomaterials makes it possible to design porous catalyzed electrodes with improved kinetics and energy efficiency. Hence, the objective of the present work is to prepare nanostructure cathode electrodes based on R-F carbon aerogels for $\mathrm{Li} / \mathrm{O}_{2}$ batteries. Many parameters influence the performance of oxygen electrode. In this work the role of porous structure of the carbon, with emphasize on the activation process, porosity and surface area measurements is explored. The electrochemical performance of the carbon aerogel based electrodes is examined by galvanostatic charge/discharge tests using a Solartron 1470 equipment.

\section{Experimental}

\subsection{Synthesis of $R / F$ aerogels}

RF aerogels were synthesized by the polycondensation of resorcinol $\left[\mathrm{C}_{6} \mathrm{H}_{4}(\mathrm{OH})_{2}\right](\mathrm{R})$ with formaldehyde [HCHO] $(\mathrm{F})$ according to the method proposed by Pekala et al. [11,12]. RF solutions were prepared by mixing the required amount of resorcinol and formaldehyde, and sodium carbonate as catalyst (C) and distilled water (W) under vigorous stirring for $45 \mathrm{~min}$. The molar ratio of $R$ to $F(R / F)$ and ratio of $R / W(g / m l)$ were constant and the molar ratio of $R$ to $C(R / C)$ was varied. The homogeneous $\mathrm{RF}$ solutions were poured into sealed glass vials to prevent the evaporation of water during gelation and gelled by aging for $72 \mathrm{~h}$ at $363 \mathrm{~K}$ into an oven to obtain RF hydrogels. The hydrogels have structures filled with water. To remove water from their structures, the gels were solvent exchanged by immersing in acetone for three days prior to the vacuum drying. Finally, the hydrogels were dried in a vacuum oven at $353 \mathrm{~K}$ for 3 days.

\subsection{TGA analysis of aerogels}

Thermogravimetric analysis (TGA) was used to determine the pyrolysis conditions for the dried aerogels. The thermal analysis system for analysis of aerogel samples was a Mettler TGA/DSC system. Typically between 5 and $10 \mathrm{mg}$ of the gel was weighed in an alumina pan and placed on the horizontal microbalance connected to the TGA. This weight corresponded to a weight percent of $100 \%$ for sample. The sample was purged with Ar flowing at $50 \mathrm{ml} \mathrm{min}^{-1}$ for $30 \mathrm{~min}$ at $303 \mathrm{~K}$ to remove oxygen from the system. It was then heated to $1273 \mathrm{~K}$ at $10 \mathrm{~K} \mathrm{~min}^{-1}$ under $\mathrm{Ar}$ and the variation of the weight loss with temperature was determined.

\subsection{Carbonization of $R / F$ aerogels}

To study the effect of pyrolysis conditions on the porous structure of carbon aerogels, pyrolysis of the dried RF aerogels was performed at different temperatures in a tubular furnace using the following method: $3 \mathrm{~g}$ of dried gel was used in each experiment. The gel was placed in a ceramic boat and purged with Ar flowing at $200 \mathrm{ml} \mathrm{min}^{-1}$ for $30 \mathrm{~min}$ at room temperature prior to the heating program. The furnace was heated to $423 \mathrm{~K}$ at $5 \mathrm{~K} \mathrm{~min}^{-1}$ and maintained at $423 \mathrm{~K}$ for $30 \mathrm{~min}$. Then it was heated to $673 \mathrm{~K}^{-1} 5 \mathrm{~K} \mathrm{~min}^{-1}$ and held for $30 \mathrm{~min}$. It was then heated to the final pyrolysis temperature at $10 \mathrm{~K} \mathrm{~min}^{-1}$ and kept for $3 \mathrm{~h}$. The whole heating program was performed under Ar flowing at $200 \mathrm{ml} \mathrm{min}^{-1}$. After pyrolysis, the furnace was cooled in flowing Ar to room temperature.

\subsection{Activation of carbon aerogels}

The activated carbon aerogels were prepared under $\mathrm{CO}_{2}$ at different temperatures. A sample of carbon aerogel was placed in a ceramic boat at the centre of the tubular furnace and purged with Ar flowing at $200 \mathrm{ml} \mathrm{min}^{-1}$ for $30 \mathrm{~min}$ prior to heating. The sample was heated to the appropriate activation temperature at $10 \mathrm{~K} \mathrm{~min}^{-1}$. At this stage gas was changed to $\mathrm{CO}_{2}$ and the sample was kept at the activation temperature under $\mathrm{CO}_{2}$ for varying time. It was then cooled down to room temperature under Ar flowing at $200 \mathrm{ml} \mathrm{min}^{-1}$.

\subsection{Material characterization}

The porosity of RF areogels and all carbon aerogels was characterized by the analysis of nitrogen adsorption-desorption isotherms measured by an ASAP 2420 adsorption analyzer (Micromeritics) at $77 \mathrm{~K}$. The samples were evacuated at $373 \mathrm{~K}$ for $2 \mathrm{~h}$ prior to the adsorption measurements. BET method was used for surface area measurements, BJH adsorptions-desorption was used for mesopore analysis and t-plot method was used for micropore analysis. Total pore volume was calculated from the adsorbed volume of nitrogen at $P / P_{0}=0.99$ (saturation pressure). Pore size distributions were obtained by the $\mathrm{BJH}$ method from adsorption branch of the isotherms [13].

\subsection{Cell construction and electrochemical measurements}

Cathode electrodes were prepared by mixing porous carbon aerogel sample, electrolytic manganese dioxide (EMD), Kynar Flex 2801 as binder (polyvinylidene difluoride-hexafluoropropylene; PVDF/HFP $88 / 12$ by weight) and propylene carbonate (PC) (weight ratios: $11 / 19 / 15 / 55)$ according to the procedure described elsewhere $[8,10]$. The materials were placed in a glass bottle to which acetone and a stirrer bar were added and the resulting mixture was left to stir for $4 \mathrm{~h}$ to form a paste. Then the paste was spread into a $200 \mu \mathrm{m}$ thick film by an applicator. The electrode was untouched until the acetone evaporates. Disks of $1.3 \mathrm{~cm}$ diameter were then cut to make disk-like cathode electrodes.

Electrochemical cell was constructed in an argon-filled glove box. The cell consists of a stainless steel bar as anode current collector, a lithium metal foil as anode, a glass micro-fiber separator soaked with electrolyte ( $1 \mathrm{M} \mathrm{LiPF}_{6}$ in propylene carbonate), a cathode electrode, an aluminum mesh and a spring and a hollow aluminum bar on the top of it as cathode current collector. The cell parts were compressed together to ensure that the electrode contact is good and then the cell was completely sealed except for the $\mathrm{Al}$ mesh window that exposes the porous cathode to the $\mathrm{O}_{2}$ atmosphere. The cell then was exposed to $\mathrm{O}_{2}$, from $\mathrm{O}_{2}$ cylinder with a purity of $99.5 \%$, at atmospheric pressure for a minimum of $30 \mathrm{~min}$ prior to the electrochemical tests and all measurements 
Table 1

Surface characteristics of aerogel samples.

\begin{tabular}{|c|c|c|c|c|c|c|c|c|c|c|}
\hline Sample & $\mathrm{R} / \mathrm{F}$ & $\mathrm{R} / \mathrm{C}$ & $\mathrm{R} / \mathrm{W}(\mathrm{g} / \mathrm{ml})$ & $S_{\mathrm{BET}}\left(\mathrm{m}^{2} / \mathrm{g}\right)$ & $V_{\text {total }}\left(\mathrm{cm}^{3} / \mathrm{g}\right)$ & $V_{\text {micro }}\left(\mathrm{cm}^{3} / \mathrm{g}\right)$ & $V_{\text {meso }}\left(\mathrm{cm}^{3} / \mathrm{g}\right)$ & $\% V_{\text {micro }}$ & $\% V_{\text {meso }}$ & $D_{\text {avg }}(\mathrm{nm})$ \\
\hline RF001 & 0.50 & 100 & 0.1 & 278 & 0.1797 & 0.1189 & 0.0608 & 66 & 34 & 2.58 \\
\hline RF002 & 0.50 & 200 & 0.1 & 417 & 0.5301 & 0.1801 & 0.350 & 33 & 67 & 5.10 \\
\hline RF003 & 0.50 & 500 & 0.1 & 149 & 0.632 & 0.0075 & 0.6245 & 2 & 98 & 16.96 \\
\hline RF004 & 0.50 & 600 & 0.1 & 182 & 1.0631 & 0.0132 & 1.0499 & 1.2 & 98.8 & 23.34 \\
\hline
\end{tabular}

were carried out under $\mathrm{O}_{2}$ atmosphere at $298 \mathrm{~K}$. Galvanostatic charge/discharge tests were performed by a Solartron 1470 potentiostat by applying a constant current in the voltage range between 2 and $4.5 \mathrm{~V}$.

\section{Results and discussion}

\subsection{BET analysis of RF aerogels}

Fig. 1 shows $\mathrm{N}_{2}$ adsorption-desorption isotherms at $77 \mathrm{~K}$ for $\mathrm{RF}$ aerogels with different $\mathrm{R} / \mathrm{C}$ ratios. All isotherms are type IV showing adsorption hysteresis which indicates the presence of mesopores [13]. For RF001 and RF002 samples with $R / C=100$ and 200 the initial region of the isotherms experiences a sharper rise at low $P / P_{0}$ indicating the presence of micropores in addition to mesopores in the gel structure.

Hysteresis loops for RF003 and RF004 gels with R/C = 500 and 600 in the $P / P_{0}$ range $0.2-1.0$ show that mesoporosity is dominant in their structures. The lower part of the hysteresis loops represent the filling of the mesopores while the upper parts represent the emptying of the mesopores $[13,14]$. It can be seen that the isotherms are shifted to the right at higher relative pressures with increase in $\mathrm{R} / \mathrm{C}$ ratio. This indicates the development of mesoporosity and formation of larger mesopores during gelation process at higher $\mathrm{R} / \mathrm{C}$ ratios.

The pore size distribution (PSD) of RF gel samples are shown in Fig. 2. The RF001 sample with $R / C=100$ shows the narrowest PSD with a maxima around pores of $2 \mathrm{~nm}$ diameter. For RF002 sample with $\mathrm{R} / \mathrm{C}=200$ the PSD is wider and the maxima is shifted to pores of $7 \mathrm{~nm}$ diameter. For RF003 and RF004 samples with $\mathrm{R} / \mathrm{C}=500$ and 600 the pore size distribution curves are even wider and show that the maxima are shifted to the right and located around $22 \mathrm{~nm}$ and $40 \mathrm{~nm}$, respectively. This shows the relationship between mesoporous structure and $\mathrm{R} / \mathrm{C}$ ratio clearly. The data in Table 1 show a significant increase in total pore volume and mesopose volume when $\mathrm{R} / \mathrm{C}$ ratio increases from 100

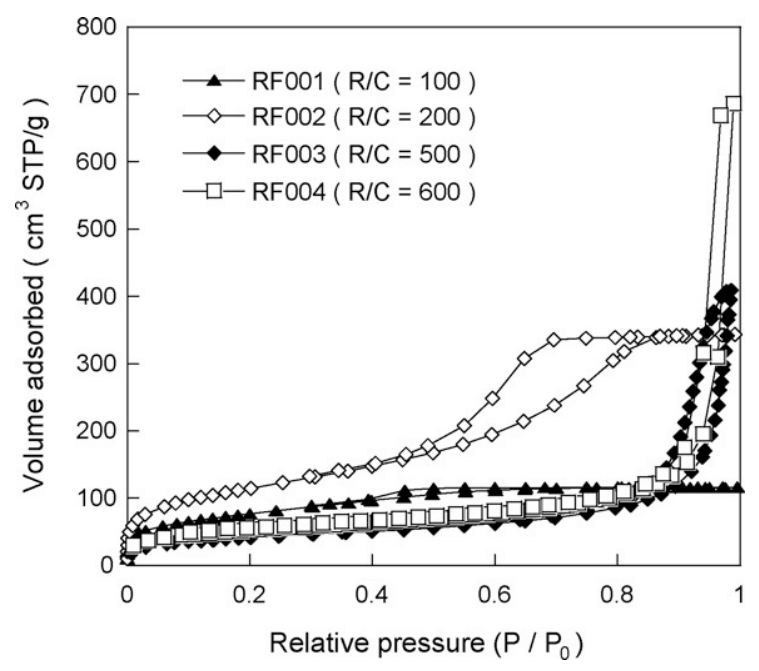

Fig. 1. $\mathrm{N}_{2}$ adsorption-desorption isotherms at $77 \mathrm{~K}$ to 600 . The mean pore size markedly increases with the $\mathrm{R} / \mathrm{C}$ ratio.

Tamon et al. have shown that during the polycondensation process, resorcinol and formaldehyde are consumed to form highly cross-linked particles. The aggregated particles become interconnected after gelation showing a structure composed of rings of particles with 20-50 particles per ring [15]. The particle size ranges from 3 to $20 \mathrm{~nm}$ and increases with $\mathrm{R} / \mathrm{C}$ ratio [16]. Hence the $\mathrm{R} / \mathrm{C}$ ratio is the principal parameter that controls the size of interconnected particles leading the scale and size of pores in the gel structure.

\subsection{Effect of pyrolysis conditions on the porous structure of the gels}

Fig. 3 shows adsorption-desorption isotherms of nitrogen at $77 \mathrm{~K}$ on RF001 aerogel with R/C ratio of 100 and CRF001-x carbon aerogels prepared by pyrolysis of the gel at different temperatures where $\mathrm{x}$ is pyrolysis temperature. Adsorption-desorption isotherms suggest that the amounts of $\mathrm{N}_{2}$ adsorbed by carbon aerogels increases with increase in the carbonization temperature for $T \leq 1073 \mathrm{~K}$. These results mean that pore volume of carbon gels increases with increasing the temperature in this range.

As the carbonization temperature increases to $1073 \mathrm{~K}$, carbonization process modifies the porous structure of the original gel and creates more micropores in the structure by releasing volatile matters during carbonization. Evidence for this comes from the sharp rise at the initial region of the isotherms $\left(P / P_{0}<0.01\right)$ which is indicative of the presence of micropores in carbon aerogels.

Fig. 3 also shows that for the carbonization temperature above $1073 \mathrm{~K}$, the amount of nitrogen adsorbed by carbon aerogels decreased which shows a decrease in the pore volume of the carbon aerogel. This is probably due to the collapse of the porous structure at high temperatures. Changes in the pore parameters of the carbon aerogels with heat treatment temperatures are listed in Table 2.

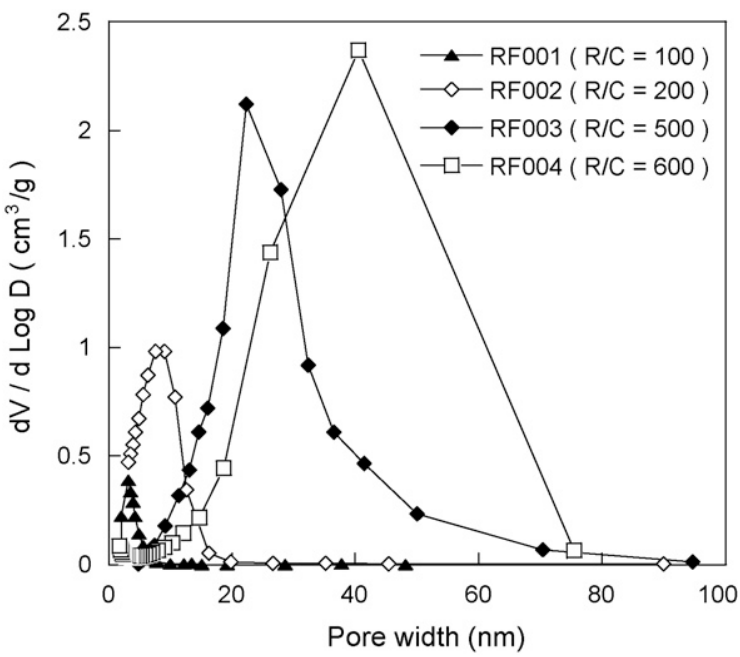

Fig. 2. Pore size distribution of RF gels with for $\mathrm{RF}$ aerogels with different $\mathrm{R} / \mathrm{C}$ ratios Various $\mathrm{R} / \mathrm{C}$ ratios. 
Table 2

Surface characteristics of the RF001 aerogel and CRF001carbon aerogels.

\begin{tabular}{|c|c|c|c|c|c|c|c|c|}
\hline Sample & Temperature (K) & $S_{\text {BET }}\left(\mathrm{m}^{2} / \mathrm{g}\right)$ & $V_{\text {total }}\left(\mathrm{cm}^{3} / \mathrm{g}\right)$ & $V_{\text {micro }}\left(\mathrm{cm}^{3} / \mathrm{g}\right)$ & $V_{\text {meso }}\left(\mathrm{cm}^{3} / \mathrm{g}\right)$ & $\% V_{\text {micro }}$ & $\% V_{\text {meso }}$ & $D_{\text {avg }}(\mathrm{nm})$ \\
\hline RF001 & - & 278 & 0.1797 & 0.1189 & 0.0608 & 66 & 34 & 2.58 \\
\hline CRF001-873 K & 873 & 286 & 0.1870 & 0.1484 & 0.0386 & 79 & 21 & 2.33 \\
\hline CRF001-973 K & 973 & 524 & 0.2874 & 0.2625 & 0.0249 & 91 & 9 & 2.27 \\
\hline CRF001-1073 K & 1073 & 669 & 0.3800 & 0.3300 & 0.0500 & 86 & 14 & 2.19 \\
\hline CRF001-1273 K & 1273 & 520 & 0.2905 & 0.2603 & 0.0302 & 89 & 11 & 2.23 \\
\hline
\end{tabular}

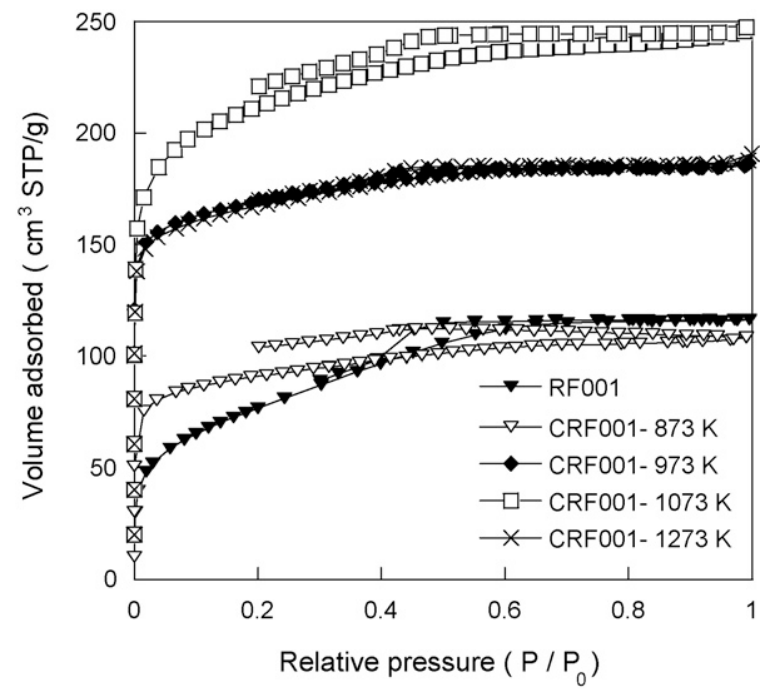

Fig. 3. $\mathrm{N}_{2}$ adsorption-desorption isotherms at $77 \mathrm{~K}$.

The data given in Table 2 shows that both total surface area and total pore volume of the carbon aerogels increase with carbonization temperature for temperatures below $1073 \mathrm{~K}$. Heat treatment of carbon aerogel above $1073 \mathrm{~K}$ decreases both surface area and total pore volume. Carbon aerogel prepared at $1073 \mathrm{~K}$ showed the maximum BET surface area and total pore volume. These results show that a temperature of $1073 \mathrm{~K}$ is the most effective for the development of the pore structure of the gel.

Fig. 4 shows the pore size distribution for RF001 aerogel and CRF001 carbons prepared at different temperatures. The PSD curves show that carbonization process decreases volume of pores for pores with diameters in the range of 3 to $10 \mathrm{~nm}$ significantly. It

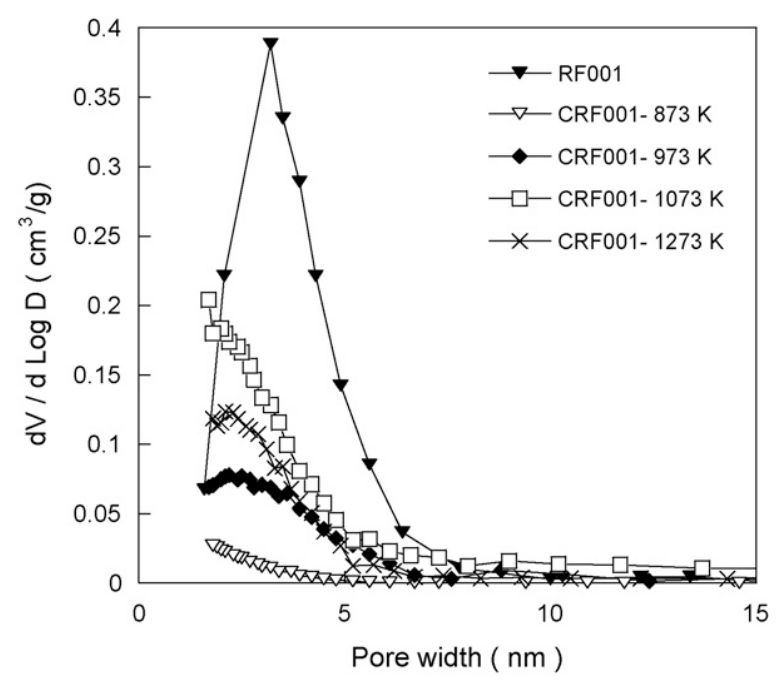

Fig. 4. Pore size distribution of RF001 and for RF001and CRF001 samples. CRF001 samples. can be seen that the PSD curves are shifted to smaller diameters after carbonization probably due to the shrinkage of the aerogel structure during the carbonization process.

Data in Table 2 suggest that decrease in the mesoprosity of the gel is at the expense of an increase in microporosity during carbonization.

Fig. 5 shows the weight loss versus temperature and derivative plots for a dried resorcinol formaldehyde gel. The TGA plot (Fig. 5a) shows that the sample mass does not change with temperatures above $1073 \mathrm{~K}$ and the derivative plot (Fig. $5 \mathrm{~b}$ ) shows that the significant mass losses occur at about 423, 673 and $873 \mathrm{~K}$. These peaks are due to the desorption of water and carbonization reactions involving breakage of $\mathrm{C}-\mathrm{O}$ bonds at $673 \mathrm{~K}$ and $\mathrm{C}-\mathrm{H}$ bonds at $873 \mathrm{~K}$, respectively [17]. The TGA shows that above $1073 \mathrm{~K}$ there is no further weight loss.

Since we have found that $1073 \mathrm{~K}$ is the most effective temperature for porosity the effect of $\mathrm{R} / \mathrm{C}$ ratio on pore structure of carbon aerogels can be investigated.

\subsection{Effect of $R / C$ ratio on the porous structure of carbons}

The adsorption-desorption isotherms of nitrogen at $77 \mathrm{~K}$ on carbons prepared from aerogels with different $\mathrm{R} / \mathrm{C}$ ratios at $1073 \mathrm{~K}$ are shown in Fig. 6.

The isotherms for CRF001 carbon $(R / C=100)$ show a type I isotherm, indicating that this sample is microporous $[13,14]$. The initial part of isotherm shows micropore filling and the low slope of the plateau is due to multilayer adsorption on the external surface. For CRF002 sample $(R / C=200)$ the initial region of the isotherms $\left(P / P_{0}<0.01\right)$ experience a sharp rise which is indicative of micropores in the sample. The hysteresis loop in the $P / P_{0}$ range $0.4-0.8$ is indicative of mesoporosity in the structure of the carbon in addition to the presence of micropores.

In the case of CRF003 sample $(\mathrm{R} / \mathrm{C}=500)$ hysteresis loop for filling and emptying of mesopores is shifted to a higher $P / P_{0}$ range (i.e. $0.7-1.0$ ) which is associated with the presence of mesopores

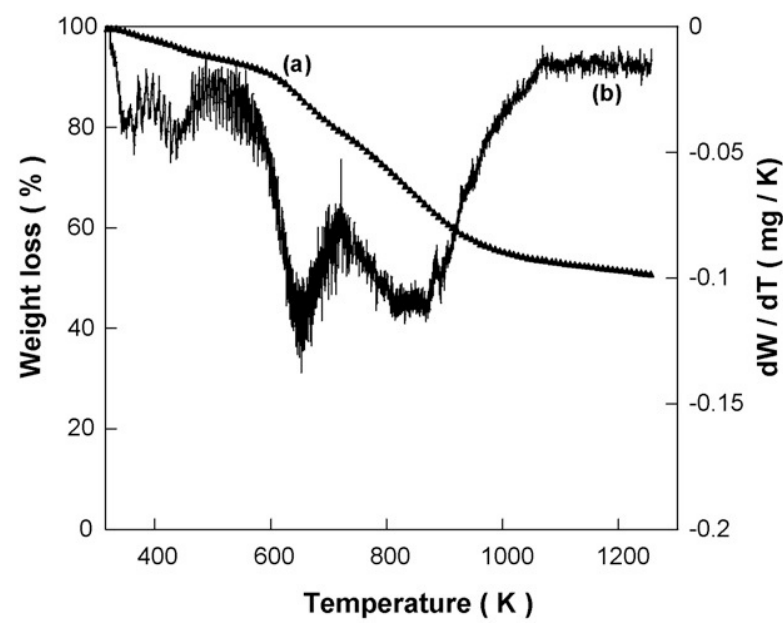

Fig. 5. Thermogravimetric analysis of a dried RF aerogel. (a) Weight \% vs. carbonization temperature. (b) Derivative thermogravimetry. 
Table 3

Porous parameters of carbon samples.

\begin{tabular}{|c|c|c|c|c|c|c|c|c|}
\hline Sample & $\mathrm{R} / \mathrm{C}$ & $S_{\mathrm{BET}}\left(\mathrm{m}^{2} / \mathrm{g}\right)$ & $V_{\text {total }}\left(\mathrm{cm}^{3} / \mathrm{g}\right)$ & $V_{\text {micro }}\left(\mathrm{cm}^{3} / \mathrm{g}\right)$ & $V_{\text {meso }}\left(\mathrm{cm}^{3} / \mathrm{g}\right)$ & $\% V_{\text {micro }}$ & $\% V_{\text {meso }}$ & $D_{\text {avg }}(\mathrm{nm})$ \\
\hline CRF001 & 100 & 669 & 0.3800 & 0.3300 & 0.0500 & 86 & 14 & 2.19 \\
\hline CRF002 & 200 & 702 & 0.714 & 0.183 & 0.531 & 26 & 74 & 6.59 \\
\hline CRF003 & 500 & 647 & 1.2245 & 0.2101 & 1.0144 & 17 & 83 & 21.65 \\
\hline CRF004 & 600 & 576 & 1.2779 & 0.2012 & 1.0767 & 16 & 84 & 25.27 \\
\hline
\end{tabular}

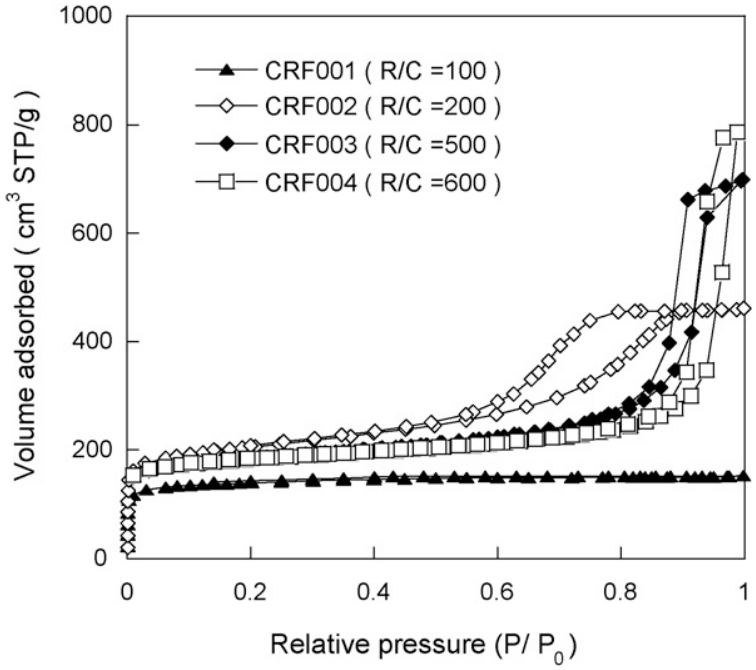

Fig. 6. $\mathrm{N}_{2}$ adsorption-desorption isotherms at $77 \mathrm{~K}$.

with larger diameters in the structure. For CRF004 carbon with R/C ratio of 600 hysteresis loop is in the $P / P_{0}$ range $0.82-1.0$ indicative of even larger mesopores in the carbon structure.

Fig. 7 Shows the PSD curves for the carbon samples. Sample CRF001 exhibits a micropore peak at the pore diameter of $2 \mathrm{~nm}$ and there is a shift of pore size distribution to pores with larger diameters as $\mathrm{R} / \mathrm{C}$ ratio increases.

The related porous parameters are listed in Table 3. It can be observed that with increase of the molar ratio of resorcinol to catalyst $(\mathrm{R} / \mathrm{C}$ ratio) from 100 to 600 in the initial gel precursors both the total pore volume and the average pore diameter of the resultant carbon aerogels increase from $0.38 \mathrm{~cm}^{3} \mathrm{~g}^{-1}$ to $1.2779 \mathrm{~cm}^{3} \mathrm{~g}^{-1}$ and $2.19 \mathrm{~nm}$ to $25.27 \mathrm{~nm}$, respectively. These results indicate that the

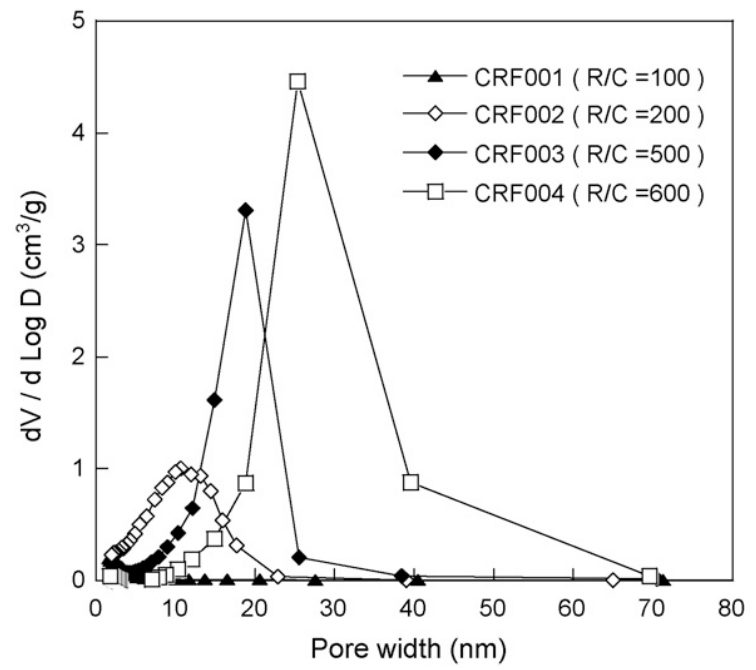

Fig. 7. Pore size distribution of carbons with for carbons with different $\mathrm{R} / \mathrm{C}$ ratios different $\mathrm{R} / \mathrm{C}$ ratios. porous structure and especially the pore volume and the pore size distribution of the aerogels and carbon aerogels can be adjusted by changing the $\mathrm{R} / \mathrm{C}$ ratio of the gel precursors.

\subsection{Effect of activation on the porous structure of carbon aerogels}

Adsorption-desorption isotherms of nitrogen at $77 \mathrm{~K}$ for CRF002 carbon aerogel and ACRF002 activated carbon aerogels obtained by $\mathrm{CO}_{2}$ activation of CRF002 carbon aerogel at different temperatures for varying times are shown in Fig. 8. Activated carbons are named as ACRF002- $\mathrm{x}$ where $\mathrm{x}$ is activation temperature.

The adsorption-desorption isotherms show a steep increase in the amount of gas adsorbed at $P / P_{0}<0.01$. This shows that large quantity of micropores have been introduced into the carbon aerogel after physical activation [18]. This might be due to the creation of new micropores by oxidation of certain structural components and opening of previously inaccessible pores [19].

Hysteresis loops in the $P / P_{0}$ range $0.4-0.9$ are indicative of mesoporosity in carbons. The lower part of the hysteresis loops represent the filling of the mesopores while the upper parts represent the emptying of the mesopores $[13,14]$. It can be observed that hystetesis loops for activated carbons shift vertically to higher adsorbed volumes at higher activation temperatures. This means that increasing the degree of burn off increases the amount of gas adsorbed by sample which is indicative of the development of porosity in the carbon structure. For all isotherms shown in Fig. 8 hysteresis loops are located almost over the same $P / P_{0}$ range (i.e. 0.4-0.9) indicating that the activation process does not affect the size of pores and pore size distribution significantly.

Fig. 9 also show that for all samples, the PSD curves are centered at the same pore diameter range (i.e. around $10 \mathrm{~nm}$ ) indicating all carbon samples are mainly mesoporous materials and possess similar pore sizes and pore size distributions. Porous parameters of carbon samples activated at different degrees of burn off are given in Table 4. It can be observed that although the average diameters of pores for all samples are similar, there is a significant increase

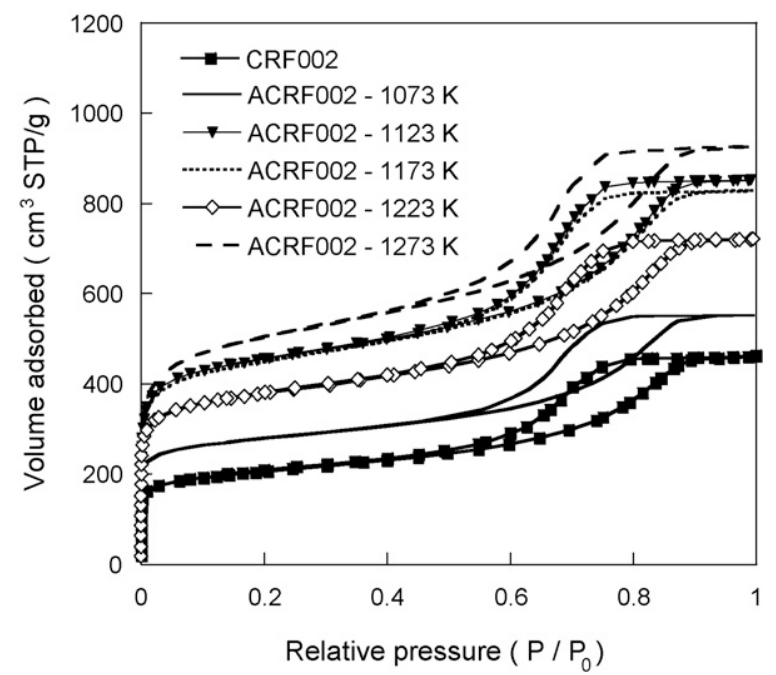

Fig. 8. $\mathrm{N}_{2}$ adsorption-desorption isotherms at $77 \mathrm{~K}$. 
Table 4

Porous parameters of CRF002 carbon samples activated at different degrees of burn off.

\begin{tabular}{|c|c|c|c|c|c|c|c|c|c|}
\hline Sample & Time (min) & Burn off \% & $S_{\text {BET }}\left(\mathrm{m}^{2} / \mathrm{g}\right)$ & $V_{\text {total }}\left(\mathrm{cm}^{3} / \mathrm{g}\right)$ & $V_{\text {micro }}\left(\mathrm{cm}^{3} / \mathrm{g}\right)$ & $V_{\text {meso }}\left(\mathrm{cm}^{3} / \mathrm{g}\right)$ & $\% V_{\text {micro }}$ & $\% V_{\text {meso }}$ & $D_{\text {avg }}(\mathrm{nm})$ \\
\hline CRF002 & - & 0 & 702 & 0.714 & 0.183 & 0.531 & 26 & 74 & 6.59 \\
\hline ACRF002- $1073 \mathrm{~K}$ & 180 & 15.72 & 946 & 0.855 & 0.282 & 0.573 & 33 & 67 & 6.47 \\
\hline ACRF002- $1123 \mathrm{~K}$ & 120 & 43.76 & 1545 & 1.320 & 0.450 & 0.87 & 31 & 69 & 6.10 \\
\hline ACRF002- $1173 \mathrm{~K}$ & 60 & 49.82 & 1531 & 1.282 & 0.431 & 0.851 & 34 & 66 & 5.85 \\
\hline ACRF002- $1223 \mathrm{~K}$ & 30 & 65.40 & 1290 & 1.115 & 0.369 & 0.746 & 33 & 67 & 6.15 \\
\hline ACRF002- $1273 \mathrm{~K}$ & 20 & 67.00 & 1725 & 1.434 & 0.427 & 1.007 & 30 & 70 & 5.60 \\
\hline
\end{tabular}

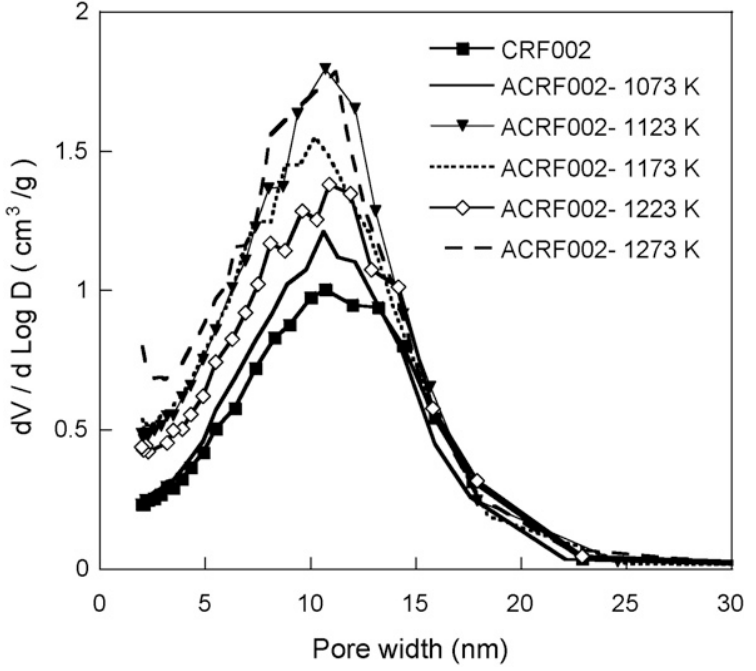

Fig. 9. Pore size distribution of ACRF002 for ACRF002 carbons at various temperatures. carbons at various temperatures.

in pore volume of the samples with burn off. Porous parameters of two samples activated at $1173 \mathrm{~K}$ and $1223 \mathrm{~K}$ show a decrease in the adsorption capacity even though the degree of burn off has increased. The decrease in pore volume and BET surface area may be due to the pore blockage and collapse at this temperature range $[20,21]$.

The porous parameters of ACRF002- $1273 \mathrm{~K}$ carbon activated at $1273 \mathrm{~K}$, given in Table 4 show that activation at a temperature higher than $1223 \mathrm{~K}$ results in a higher degree of burn off, opening the collapsed and blocked porous structure and increasing the pore volume and BET area significantly.

Fig. 9 shows that the porosity development mainly takes place in the range of small mesopores (i.e. pore diameter $\leq 10 \mathrm{~nm}$ ). According to these results, increase in the degree of burn off increases the pore volume, without affecting the mean pore diameter probably due to the creation and widening of micropores and also opening of more mesopores.

In order to prepare carbon samples with larger mesopores and higher pore volumes, CRF003 carbon is activated at different temperatures and varying times. Activated carbons are named as ACRF003- $\mathrm{x}$ where $\mathrm{x}$ is activation temperature and the corresponding $\mathrm{N}_{2}$ adsorption- desorption isotherms are shown in Fig. 10. These isotherms show that the higher the degree of burn off, the greater the amount of adsorption. Fig. 11 shows that such an activation treatment results in activated carbons with high pore volumes and average pore diameters of around $15 \mathrm{~nm}$. Porosity development takes place in the range of large mesopores (i.e. pore diameter $\sim 20 \mathrm{~nm})$.

Data given in Table 5 shows that activation at $1323 \mathrm{~K}$ produces a large increase in the pore characteristics such as total and mesopore volumes and BET surface area.

Results given in Section 3 show that the porous structure of carbon aerogels can be engineered on a nanometre scale by chang-

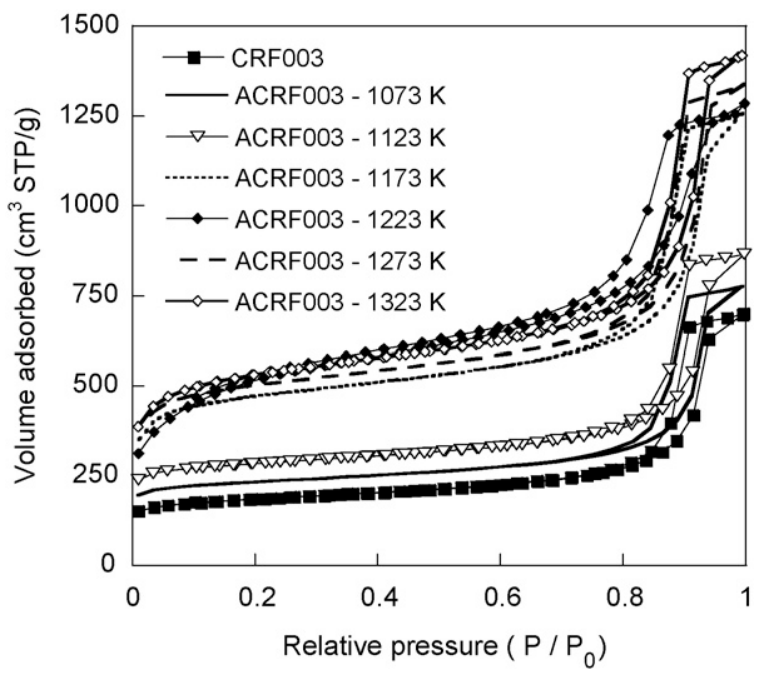

Fig. 10. $\mathrm{N}_{2}$ adsorption-desorption isotherms at $77 \mathrm{~K}$.

ing the molar ratio of resorcinol to catalyst during gel preparation and also carbonization and activation under $\mathrm{CO}_{2}$ atmosphere at different temperatures. Some of these carbons have been utilized as active materials for electrode fabrication and their electrochemical performance is tested in a lithium oxygen cell as follow.

\subsection{Electrochemical measurements}

All the data reported below are obtained from the galvanostatic charge/discharge of the cells described above with reproducibility to less than $5 \%$ error in the cell capacities.

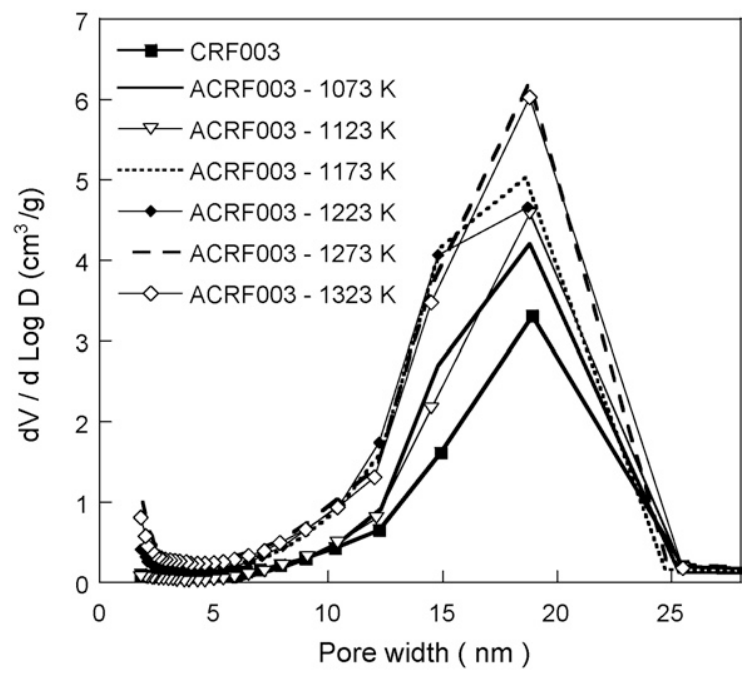

Fig. 11. Pore size distribution of ACRF003 for ACRF003 carbons at various temperatures. carbons at various temperatures. 
Table 5

Porous parameters of CRF003 carbon samples activated at different degrees of burn off.

\begin{tabular}{|c|c|c|c|c|c|c|c|c|c|}
\hline Sample & Time (min) & Burn off $\%$ & $S_{\text {BET }}\left(\mathrm{m}^{2} / \mathrm{g}\right)$ & $V_{\text {total }}\left(\mathrm{cm}^{3} / \mathrm{g}\right)$ & $V_{\text {micro }}\left(\mathrm{cm}^{3} / \mathrm{g}\right)$ & $V_{\text {meso }}\left(\mathrm{cm}^{3} / \mathrm{g}\right)$ & $\% V_{\text {micro }}$ & $\% V_{\text {meso }}$ & $D_{\text {avg }}(\mathrm{nm})$ \\
\hline CRF003 & - & 0 & 647 & 1.2245 & 0.2101 & 1.0144 & 17 & 83 & 21.65 \\
\hline ACRF003- $1073 \mathrm{~K}$ & 150 & 9.7 & 732 & 1.200 & 0.253 & 0.947 & 21 & 79 & 16.77 \\
\hline ACRF003- $1123 \mathrm{~K}$ & 125 & 21 & 891 & 1.336 & 0.313 & 1.023 & 24 & 76 & 15.93 \\
\hline ACRF003- $1173 \mathrm{~K}$ & 120 & 54 & 1497 & 1.942 & 0.448 & 1.494 & 23 & 77 & 15.43 \\
\hline ACRF003- $1223 \mathrm{~K}$ & 60 & 58 & 1506 & 1.965 & 0.434 & 1.531 & 22 & 78 & 15.01 \\
\hline ACRF003- $1273 \mathrm{~K}$ & 30 & 65 & 1585 & 2.075 & 0.488 & 1.587 & 23 & 77 & 14.76 \\
\hline ACRF003- $1323 \mathrm{~K}$ & 20 & 67 & 1687 & 2.195 & 0.463 & 1.732 & 21 & 79 & 14.23 \\
\hline
\end{tabular}

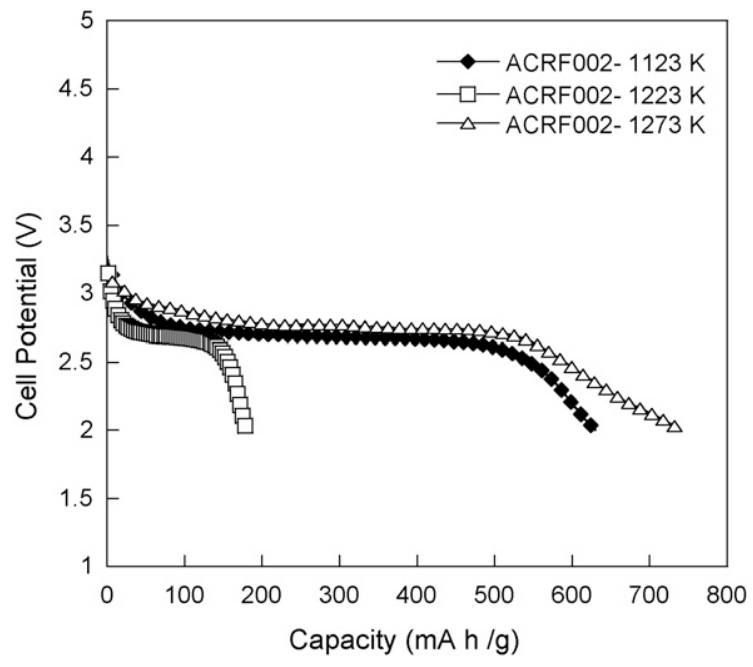

Fig. 12. Discharge capacities of ACRF002.

EMD used in the electrode formulation was purchased from Sigma and used as received. It aids the $\mathrm{Li}_{2} \mathrm{O}_{2}$ decomposition and charging process [8] and also catalyzes the reduction of $\mathrm{O}_{2}$ to $\mathrm{O}^{2-}$ on the cathode electrode during discharge process [7]. Although EMD is an intercalation host for Li and some of discharge reaction may take place on its surface [10], however it does not contribute to the discharge capacity significantly as its contribution to the discharge capacity is reported to be at most $16 \mathrm{~mA} \mathrm{~h} \mathrm{~g}^{-1}$ [8]. Assuming that the products of the discharge reaction in $\mathrm{Li} / \mathrm{O}_{2}$ cell deposit only onto carbon, the capacity of the lithium/oxygen cells has been normalized to the weight of carbon in the cathode electrode.

\subsubsection{Effect of pore}

Volume Fig. 12 shows discharge behavior of the $\mathrm{Li} / \mathrm{O}_{2}$ cells (first cycles) based on electrodes prepared from ACRF002 carbons with similar pore sizes and pore size distributions but different pore volumes. Variations of cell voltage against specific capacity of carbon samples at a discharge rate of $20 \mathrm{~mA} / \mathrm{g}$ show flat discharge profiles at about $2.7-2.9 \mathrm{~V}$. These are associated with the storage behavior of the cells and are in good agreement with the preceding reported data for a similar cell discharged in $\mathrm{O}_{2}$ at atmospheric pressure involving formation of $\mathrm{Li}_{2} \mathrm{O}_{2}$ as discharge product $[7,8]$.

Table 6 shows how discharge voltage and capacity vary with change in the structure of carbons used in electrode formulation. It can be seen that the storage capacity increases with increase in the level of burn off and development of mesoporosity in car-

Table 6

Discharge capacities of ACRF002 carbons with various pore volumes.

\begin{tabular}{lll}
\hline Sample & Cell voltage $(\mathrm{V})$ & Discharge capacity $(\mathrm{mAh} / \mathrm{g})$ \\
\hline ACRF002-1123 K & 2.60 & 630 \\
ACRF002-1223 K & 2.68 & 180 \\
ACRF002-1273 K & 2.76 & 740 \\
\hline
\end{tabular}

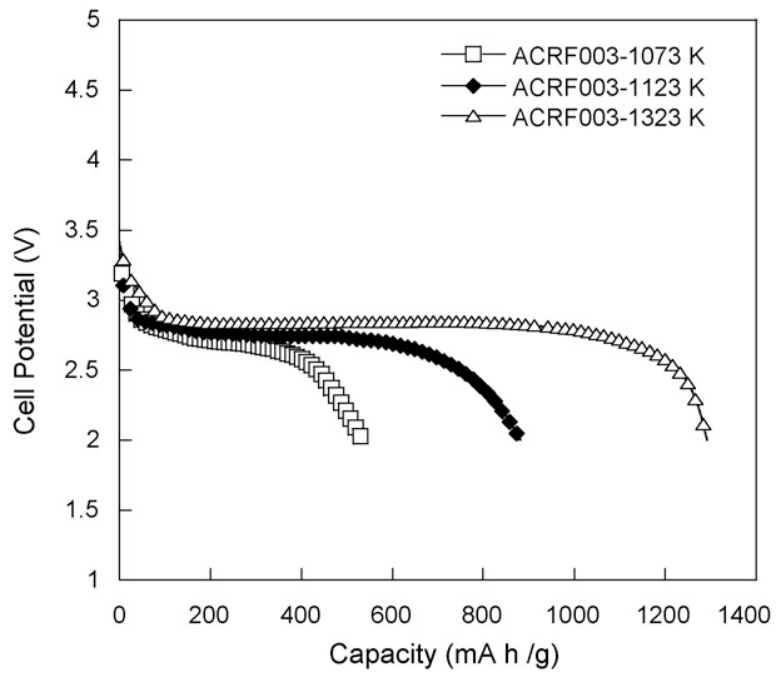

Fig. 13. Discharge capacities of ACRF003 carbons discharged at $20 \mathrm{~mA} / \mathrm{g}$. carbons discharged at $20 \mathrm{~mA} / \mathrm{g}$

bons. Sample ACRF002- $1273 \mathrm{~K}$ with the highest mesopore volume showed the highest storage capacity of $740 \mathrm{~mA} \mathrm{~h} \mathrm{~g}^{-1}$ and sample ACRF002- $1223 \mathrm{~K}$ with the lowest mesopore volume showed the lowest storage capacity of $180 \mathrm{mAh} \mathrm{g}^{-1}$ between three ACRF002 carbon samples.

Fig. 12 shows that the discharge voltage of a $\mathrm{Li} / \mathrm{O}_{2}$ cell depends on the morphology of the carbon used in its cathode electrode. This might be due to the change in the conductivity of carbons as their pore volumes are different.

Activated carbons ACRF003 with similar pore sizes and pore size distributions but different pore volumes have also been tested. Discharge capacities of these carbons at a discharge rate of $20 \mathrm{~mA} / \mathrm{g}$ are shown in Fig. 13.

Fig. 13 also shows that a carbon with higher pore volume possesses higher discharge capacity. It is believed that larger pore volume provides more space for the formation and storage of $\mathrm{Li}_{2} \mathrm{O}_{2}$ during the discharge process as the end-of-discharge of the cell is reached when the carbon pores are filled or choked by the deposition of $\mathrm{Li}_{2} \mathrm{O}_{2}$, however as this is not clear yet, further work is underway to understand the role of pore volume on the storage capacity.

Discharge capacities and voltages of ACRF003 carbons used in electrode formulation are given in Table 7.

Table 7

Discharge capacities of ACRF003 carbons with various pore volumes.

\begin{tabular}{llc}
\hline Sample & Cell voltage $(\mathrm{V})$ & Discharge capacity $(\mathrm{mA} \mathrm{h} / \mathrm{g})$ \\
\hline ACRF003-1073K & 2.68 & 528 \\
ACRF003-1123K & 2.74 & 880 \\
ACRF003-1323K & 2.83 & 1290 \\
\hline
\end{tabular}




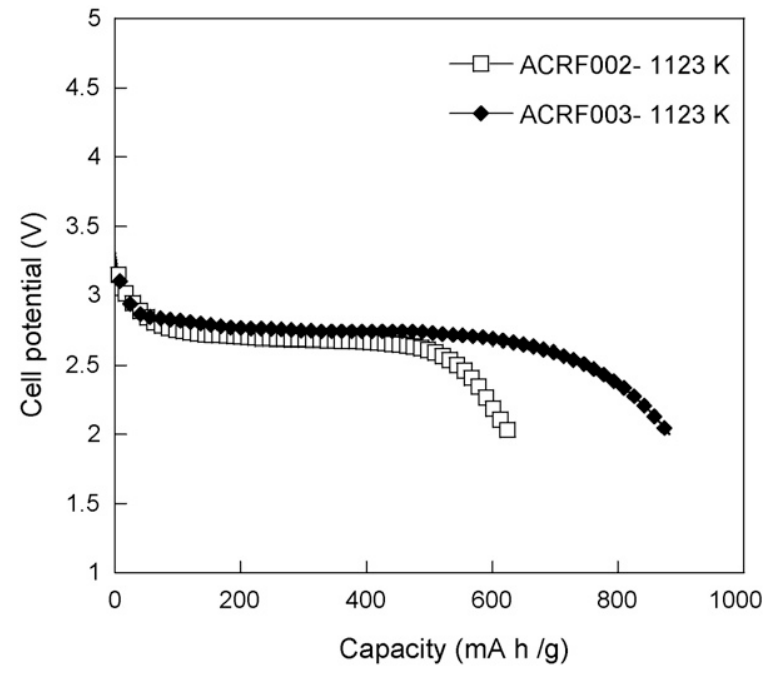

Fig. 14. Discharge capacities of carbons with different pore size.

Table 8

Discharge capacities of carbons with various pore size.

\begin{tabular}{lll}
\hline Sample & Cell voltage $(\mathrm{V})$ & Discharge capacity $(\mathrm{mAh} / \mathrm{g})$ \\
\hline ACRF003-1073 K & 2.68 & 528 \\
ACRF003-1123 K & 2.74 & 880 \\
\hline
\end{tabular}

\subsubsection{Effect of pore size}

Fig. 14 compares the discharge capacities of two carbons with similar pore volumes but different pore diameters. Carbon with larger pore diameter exhibits a larger discharge capacity.

Pores in carbon electrode allow both the oxygen and electrolyte to come in contact with the carbon and catalyst. The electrochemical reduction of oxygen takes place on the carbon surface. It is important to minimize diffusion barriers to increase storage capacity of $\mathrm{Li} / \mathrm{O}_{2}$ cells by tailoring carbon electrodes having appropriate porous structures and pore sizes that maximize electrolyte and oxygen accessibility to the porous network.

The storage capacity is linked to the physical surface area, to the pore size and to the ionic accessibility of the electrode active material. In order to obtain a reasonable storage capacity and energy density, the electrode pore volume, pore size distribution, and surface area should be optimized.

Table 8 shows how mesopores are important for improving the performance of $\mathrm{Li} / \mathrm{O}_{2}$ cells. They lead the electrolyte ions transport into the bulk of material quickly and also provide larger space for formation of discharge products. Therefore a sample with wider pores and larger pore volume might results in: higher diffusivity of the electrolyte into the carbon structure and better accessibility of lithium ions to the carbon surface (reaction zone), larger space for the storage of discharge products as larger pore volume is available in the porous structure, and finally better diffusion of oxygen to the carbon-electrolyte interface.

\section{Conclusions}

Porous activated carbons were synthesized through polycondensation of resorcinol with formaldehyde followed by carbonization at $1073 \mathrm{~K}$ in an inert atmosphere and activation under $\mathrm{CO}_{2}$ at different temperatures. Activation at higher temperatures increased total and meso pore volumes while the pore size distribution of the samples remained almost constant.

Activated carbons were used as active materials in cathode electrodes for $\mathrm{Li} / \mathrm{O}_{2}$ batteries and their electrochemical behavior was characterized by constant current charge/discharge experiments.

Associating the discharge capacity with the textural parameters of the porous carbons showed that the appropriate pore volume and pore diameter are the key factors contributing to high capacity. It was shown that the discharge voltage of a $\mathrm{Li} / \mathrm{O}_{2}$ cell depends on the morphology of the carbon used in its oxygen electrode and a combined effect of pore volume, pore size and surface area of carbon affects the storage capacity. $\mathrm{A} \mathrm{Li} / \mathrm{O}_{2}$ cell using the carbon with the largest pore volume $\left(2.195 \mathrm{~cm}^{3} \mathrm{~g}^{-1}\right)$ and a wide pore size $(14.23 \mathrm{~nm})$ showed a specific capacity of $1290 \mathrm{~mA} \mathrm{~h} \mathrm{~g}^{-1}$ and discharge voltage of $2.83 \mathrm{~V}$.

\section{Acknowledgments}

We thank the EPSRC for funding as part of the Supergen Energy Storage Consortium (grant code EP/D031672/1).

\section{References}

[1] M. Armand, J.M. Tarascon, Nature 451 (2008) 652.

[2] M. Endo, C. Kim, K. Nishimura, T. Fujino, K. Miyashita, Carbon 38 (2000) 183.

[3] J.P. Gabano, Lithium Batteries, Academic press, New York, 1983.

[4] D. Linden, B.T. Reddy, Hand Book of Batteries, 3rd ed., McGraw-Hill, New York, 1989.

[5] S. Flandrois, B. Simon, Carbon 37 (1999) 165.

[6] R. Yazami, Ph. Touzain, J. Power Sources 9 (1983) 365

[7] K.M. Abraham, Z.J. Jiang, J. Electrochem. Soc. 143 (1996) 1.

[8] T. Ogasawara, A. Debart, M. Holzapfel, P. Novak, P.G. Bruce, J. Am. Chem. Soc. 128 (2006) 1390

[9] J. Read, K. Mutolo, M. Ervin, W. Behl, J. Wolfenstine, A. Driedger, D. Foster, J. Electrochem. Soc. 150 (2003) A1351.

[10] J. Read, J. Electrochem. Soc. 149 (2002) A1190

[11] R.W. Pekala, J. Mat. Sci. 24 (1989) 322.

[12] R.W. Pekala, W. Schaefer, Macromolecules 26 (1993) 5487.

[13] F. Rouquerol, J. Rouquerol, K.S.W. Sing, Adsorption by powders and porous solids, in: Principles Methodology and Applications, Academic Press, New York, 1999.

[14] S.J. Gregg, K.S.W. Sing, Adsorption Surface area and Porosity, Academic Press, New York, 1967.

[15] H. Tamon, H. Ishizaka, M. Mikami, M. Okazaki, Carbon 35 (1997) 791.

[16] G.C. Ruben, R.W. Pekala, T.M. Tillotson, L.W. Hrubesh, J. Mater. Sci. 27 (1992) 4341.

[17] C. Lin, J.A. Pitter, Carbon 35 (1997) 1271

[18] M. Kruk, M. Jaroniec, K.P. Gadkaree, J. Colloid. Interface. Sci. 192 (1997) 250.

[19] H. Marsh, B. Rand, Carbon 9 (1971) 47.

[20] D. Mowla, D.D. Do, K. Kaneko, in: L.R. Radovic (Ed.), Chemistry and Physics of Carbon, vol. 28, Marcel Dekker, New York, 2003, pp. 229-262.

[21] Y. Yan, J. Wei, F. Zhang, Y. Meng, B. Tu, D. Zhao, Micropor. Mesopor. Mater. 113 (2008) 305. 